\title{
Atrial fibrillation and hyperthyroidism : a new look at their relationship and therapy with lidoflazine
}

\author{
K. BRUYNEEL ${ }^{*} \dagger$ \\ M.D.
}

H. VERHAEGEN*
M.D.

\author{
CH. De VIL $\ddagger$ \\ M.D. \\ * Clinical Research Unit, St Bartholomeus Hospital, B-2060 Merksem, Belgium \\ $\ddagger$ Department of Internal Medicine, H. Hartziekenhuis, B-2500 Lier, Belgium
}

\begin{abstract}
Summary
Various kinds of dysrhythmias are found in association with hyperthyroidism but especially atrial fibrillation. The causal relationship of chronic atrial fibrillation and the endocrine disorder is controversial, as is its therapeutic management. Six patients with this particular combination of disorders were treated with lidoflazine: a new anti-anginal drug with antiarrhythmic activity. All six patients returned to sinus rhythm on lidoflazine treatment although still hyperthyroid and remained in sinus rhythm during the follow up period ranging from 5 to 14 months. This occurred independently of antithyroid treatment. Some evidence is put forward that dysrhythmias and most commonly chronic atrial fibrillation are triggered off by hyperthyroidism or other disorders but that they are maintained by permanent cardiac damage due to arteriosclerosis, hypertension, coronary heart disease or rheumatic valve disease.
\end{abstract}

Successful chemical cardioversions and maintenance of sinus rhythm can be obtained independent of the thyroid function. Our results confirm the antiarrhythmic activity of lidoflazine.

\section{Introduction}

Hyperthyroidism has been found to be associated not only with sinus tachycardia, one of its features, but also with several dysrhythmias and conduction disturbances such as atrial flutter (Ernstene, 1938), first and second degree of a.v. block (Cookson, 1959; Blizzard and Rupp, 1960; Hoffman and Lowrey, 1960; Rosenblum and Delman, 1963; Lanfranchi and Fauchier, 1973), third degree of a.v. block (Davis and Smith, 1933; Steuer, 1936;

Address for reprints: Dr H. Verhaegen, Clinical Research Unit, St Bartholomeus Hospital, B-2060 Merksem, Belgium.

$\dagger$ Present address: K. Oomsstraat 44, B-2000 Antwerp, Belgium.
Muggia, Stjernholme and Houle, 1970; Stern, Jacobs and Duncan, 1970; Kernoff, Rossouw and Kennelly, 1972), reversible bundle branch block (Digilio, 1938), ventricular ectopic beats (Rohrbach, 1968), ventricular tachycardia (Ernstene, 1938; Fairhurst and Sash, 1959; Lyngborg and Jacobsen, 1972) and ventricular fibrillation (Boone, 1945; Lyngborg and Jacobsen, 1972). These dysrhythmias, although some are rare, have been described in patients of over 40 years of age who also had coronary artery disease, hypertension or acute infections. Ernstene (1938) found 207 patients with atrial fibrillation among 1000 patients with hyperthyroidism, Bourel et al. (1969) twenty-four of eighty-three patients, Rohrbach (1968) four of eleven patients with masked hyperthyroidism, Sandler and Wilson (1959) eighty-four of 462 patients and Jervell (1952) fifty-three of 279 patients. Therefore, atrial fibrillation can be considered as the most common cardiac dysrhythmia associated with hyperthyroidism (Friedberg, 1966; Miyahara et al., 1969). It is common experience that no parallelism exists between heart rhythm and the severity of thyroid dysfunction (Friedberg, 1966). Sinus rhythm is not always restored by normalizing the thyroid function and DC shock, quinidine or combination of drug therapy is often required to restore sinus rhythm.

Lidoflazine, a new anti-anginal drug, has been sho'wn to have anti-arrhythmic activity, especially as concerns supraventricular dysrhythmias such as atrial fibrillation and flutter, in patients with arteriosclerosis, rheumatic heart disease, hypertension, congenital heart disease and lone atrial fibrillation (Miyahara et al., 1969; Piessens, Kesteloot and De Geest, 1970; Schlepper and Derro, 1972; Batlouni, unpublished report; De Vil and Bruyneel, 1974).

We have for the first time treated patients with 


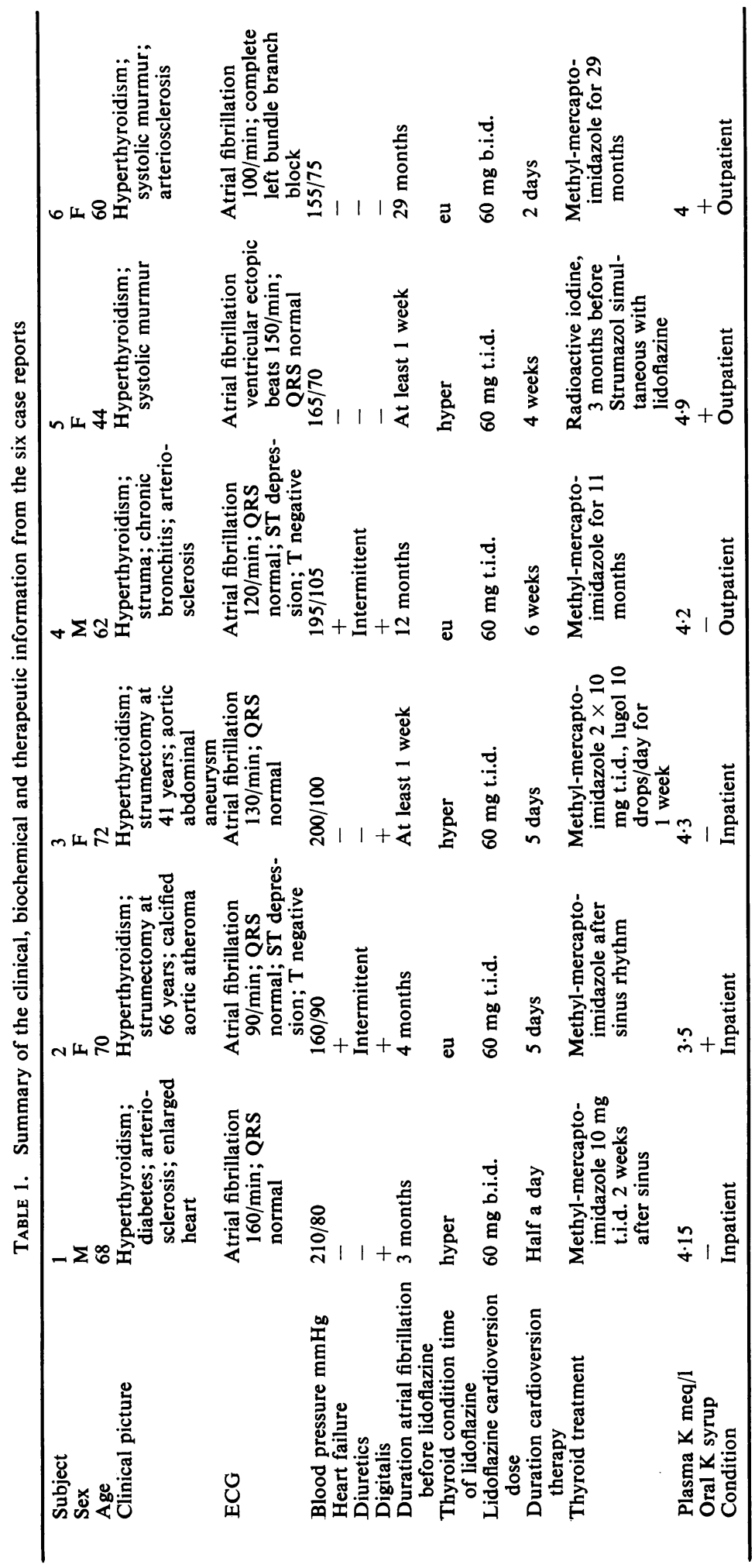


chronic atrial fibrillation and hyperthyroidism with lidoflazine. It is the purpose of this study to demonstrate that lidoflazine converts atrial fibrillation during the hyperthyroid as well as the euthyroid state, and maintains sinus rhythm independent of the thyroid function.

\section{Material and methods}

Six consecutive patients with chronic atrial fibrillation and hyperthyroidism were treated with lidoflazine tablets to obtain sinus rhythm. Atrial fibrillation was considered to be chronic when lasting continuously for at least 1 week without any previous attacks of self-limiting atrial fibrillation or palpitations in the history. Special attention was given to the potassium metabolism of the patients. Potassium syrup ( $20 \mathrm{mEq}$ potassium t.i.d.) was generally given to all patients who had diuretics, laxatives, mild heart failure, ventricular ectopic beats on the resting ECG or low serum potassium value.

Patients with manifest heart failure, special diets (low salt, low calorie) or acute coronary artery disease were excluded unless conditions were altered. No other anti-arrhythmic drug was given except digitalis when required in the presence of heart failure or fast ventricular rhythm at rest $(>100$ beats/min).

Lidoflazine tablets of $60 \mathrm{mg}$ were given, starting with one tablet a day during the first week with a weekly increase of one tablet up to three tablets a day for the outpatients. The treatment was started with two or three tablets a day at once for the inpatients. Anti-hyperthyroid treatment was started before or after the cardioversion. The cardioversion was initially attempted in the hospital but later as an outpatient treatment. Hyperthyroidism was believed to be present according to the clinical features and symptoms and when plasma cholesterol was below $150 \mathrm{mg} \%$, PBI above $9 \gamma$, basal metabolism above $+30 \%, \mathrm{~T}_{3}$ resine uptake above $35 \%, \mathrm{~T}_{4}$ above $12 \mathrm{mg} \%$.

Atrial fibrillation and sinus rhythm were diagnosed by means of repetitive 12-lead ECG recordings at rest. Lidoflazine treatment was maintained at the dose of cardioversion or less for each patient.

\section{Results}

Sinus rhythm was obtained in all six patients within half a day to 6 weeks (see Table 1). None of the patients had a history of arterial embolism or signs of mitral valve disease. Anticoagulants were given to one patient only (case 2).

\section{Case 1}

The patient continued her treatment of digitalis, lidoflazine $60 \mathrm{mg}$ b.i.d., meprobamate and methyl- mercapto-imidazole. She has remained in sinus rhythm for 8 months despite two relapses of hyperthyroidism when she stopped methyl-mercaptoimidazole (Strumazol $\left.{ }^{\otimes}\right)$ therapy.

\section{Case 2}

The patient was treated with digitalis, methylmercapto-imidazole and lidoflazine $60 \mathrm{mg}$ t.i.d. Follow-up not possible after discharge from hospital.

\section{Case 3}

The patient has remained in sinus rhythm for 14 months with lidoflazine $60 \mathrm{mg}$ b.i.d. and lugol solution, although she remains slightly hyperthyroid.

\section{Case 4}

The patient remained in sinus rhythm for 5 months taking only one tablet of lidoflazine a day during the last month. Such a low dosage treatment was considered to be ineffective and stopped. Atrial fibrillation promptly returned and remained for another 4 months. The patient, who suffered from character disturbances, refused to take lidoflazine tablets again. He died $12 \mathrm{hr}$ after a trauma from multiple bone and skull fractures.

\section{Cases 5 and 6}

Both patients have remained in sinus rhythm for 5 months while taking lidoflazine $60 \mathrm{mg}$ b.i.d. and methyl-mercapto-imidazole.

\section{Discussion}

The initial results of converting atrial fibrillation to sinus rhythm and maintaining the rhythm during mild to moderate severe hyperthyroidism look promising al though our series is rather small. No rhythm disturbances have been observed or mentioned by the patients but continuous ECG monitoring has not been undertaken during the cardioversion period. No side effects or complications were noticed. Similar cardioversion results of atrial fibrillation to sinus rhythm during hyperthyroidism have been reported with quinidine (De Vil and Bruyneel, 1974) and quinidine with propranolol (Levi and Proto, 1972). Therefore it is difficult to agree with other authors (Carlier, 1973) who consider attempts to convert atrial fibrillation during hyperthyroidism to be utopian since sinus rhythm will not remain so long as hyperthyroidism exists, and most patients convert spontaneously to sinus rhythm once hyperthyroidism is effectively treated (Schrire, 1971; Carlier, 1973). Ernstene (1938) found that of sixty cases of established atrial fibrillation, thyroidectomy resulted in a spontaneous re-establishment of sinus rhythm in twenty-one patients within 10 days after surgery. Subsequently, quinidine sulphate was started in twenty patients, 
which converted atrial fibrillation to sinus rhythm in twelve. Six patients of the remaining group died with atrial fibrillation and thirteen others persisted in their dysrhythmia.

Silver, Delit and Eller (1962) found atrial fibrillation to be present in $51 \%$ of the patients with thyrocardiac disease before and in $24 \%$ after radioactive iodine therapy.

Bock and Klein (1972) found dysrhythmias in fourteen of thirty-eight patients with hyperthyroidism who were more than 60 years old. Tachyarrhythmias were frequent during, as well as after, radioactive iodine therapy, and generally resistant to drug therapy. The authors very seldom observed a spontaneous remission to sinus rhythm in this age group.

Several authors (Ernstene, 1938; Boone, 1945; Jervell, 1952; Moe, 1968; Ticzon and Whalen, 1973) have pointed out that atrial fibrillation may occur as an acute self-limiting form triggered off by hyperthyroidism, pericarditis, pneumonia, influenza, pulmonary embolus, post-thoracotomy, gall bladder disease, alcohol or heroin intoxication. This atrial fibrillation remains chronic and refractory when permanent cardiac damage (with or without atrial enlargement due to rheumatic heart disease, hypertension, arteriosclerosis and coronary heart disease) is present. This explains why $75 \%$ of 207 patients with hyperthyroidism and atrial fibrillation were older than 45 years (Ernstene, 1938) and atrial fibrillation was found to be related with the duration of existence of hyperthyroidism (Willius, Boothby and Wilson, 1923).

Other authors (Kulbertus, 1973) could not confirm this concept. However, some evidence that atrial fibrillation is not caused by hyperthyroidism itself but, more likely, is induced by the excess of thyroid hormones and maintained only in the presence of different kinds and degrees of cardiovascular damage, is given by the following facts.

(1) Chronic atrial fibrillation associated with hyperthyroidism occurs only in patients of over 40 years of age while atrial fibrillation in the younger patients remains paroxysmal (Boone, 1945).

(2) Only $20-25 \%$ of all hyperthyroid patients develop chronic atrial fibrillation (Ernstene, 1938; Jervell, 1952; Sandler and Wilson, 1959; Rohrbach, 1968; Bourel et al., 1969).

(3) Onset and spontaneous conversion of atrial fibrillation does not correspond to onset and correction of hyperthyroidism (Willius et al., 1923; Symons, Richardson and Wood, 1971).

(4) Not all efficiently treated hyperthyroid patients with atrial fibrillation subsequently spontaneously regain sinus rhythm (Ernstene, 1938; Silver et al., 1962; Bock and Klein , 1972).

(5) Atrial fibrillation can be converted to sinus rhythm and the latter can be maintained with antiarrhythmic drugs during hyperthyroidism, independently of the antithyroid treatment or thyroid function present (Levi and Proto, 1972; De Vil and Bruyneel, 1974).

(6) Hyperthyroidism does not only trigger off atrial fibrillation but has been found to induce all kinds of dysrhythmias and conduction disturbances in patients of over 40 years of age depending on concomitant pathophysiological conditions (Cookson, 1959; Fairhurst and Sash, 1959; Lyngborg and Jacobsen, 1972).

Therefore, there is no need to leave the hyperthyroid patient, with his disturbing symptoms of palpitations or atrial fibrillation with fast ventricular rate and decreased cardiac output and effort tolerance (Benchimol, Lowe and Akre, 1965; Bouma and May, 1967), until stable euthyroid state is obtained and hoping atrial fibrillation will spontaneously convert to sinus rhythm. Although propranolol (Howitt and Rowlands, 1966), guanethidine (Lee, Bronsky and Waldstein, 1962; Waldstein et al., 1964; Goldstein and Killip, 1965) and reserpine (Canary et al., 1957) have been shown to diminish palpitations in patients with hyperthyroidism, they do not convert atrial fibrillation to sinus rhythm, and a complete return to normal conditions of heart rate and cardiac output is not achieved. Propranolol (Howitt and Rowlands, 1967) and guanethidine (Goldstein and Killip, 1965) should be used with caution in hyperthyroidism since both drugs reduce blood flow to certain vascular beds out of proportion to the oxygen demand. Another alternative is offered by lidoflazine therapy. This original compound prolongs reactive hyperaemia in mini pigs after coronary artery occlusion (Jageneau, Schaper and Van Gerven, 1969), reduces consumption of nitroglycerine tablets and improves exercise tolerance in patients with coronary heart disease (Batlouni, Bertolami and Duprat, 1968; Bernstein and Peretz, 1972; Piessens and De Geest, 1972). Lidoflazine converts atrial fibrillation to sinus rhythm in $70-80 \%$ of the patients suitable for cardioversion and the therapy compares favourably with quinidine-induced conversions (De Vil and Bruyneel, 1974).

The rate of pacemaker activity and depolarization $(d \mathrm{~V} / d \mathrm{t})$ and amplitude of the action potential and conduction velocity of in vitro cardiac muscle preparations are reduced by lidoflazine. The duration of the action potential and of the effective refractory period is prolonged (Carmeliet and Xhonneux, 1971). Lidoflazine may thus be compared to local anaesthetics and other anti-arrhythmic drugs, such as quinidine. It has no obvious chronotropic (Keulen, 1973) or inotropic (Bruyneel, personal observation) effect in the resting state. Lidoflazine is not known to interfere with the thyroid hormone metabolism or 
any of its diagnostic tests. Bernstein and Peretz (1972) found $\mathrm{QT}_{\mathrm{c}}$ to be prolonged in their patients with lidoflazine. Keulen (1973) found the $\mathrm{QT}_{\mathrm{c}}$ unchanged. Increased incidence of ventricular dysrhythmias has been reported during lidoflazine treatment in patients with atrial fibrillation and overt heart failure, enlarged heart size or conditions where decreased body potassium can be expected (Piessens et al., 1970; Schlepper and Derro, 1972). This was not the experience when classic selection criteria for cardioversion were applied (De Vil and Bruyneel, 1974).

The advantages of lidoflazine therapy seem to be the absence of side effects and drug interference and the low dosage needed to maintain sinus rhythm with excellent results after cardioversion. Batlouni (unpublished report) found twenty-eight of thirty patients with atrial fibrillation to be still in sinus rhythm 1 year after having been converted to sinus rhythm with lidoflazine. Twenty-four patients had taken one tablet daily for 1 year as maintenance therapy. Our limited experience with lidoflazine in hyperthyroid patients with atrial fibrillation accords with previous observations as concerns its efficacy to convert atrial fibrillation to sinus rhythm and its maintenance. It confirms the intrinsic antiarrhythmic effect of lidoflazine which is obvious within a few days or weeks in contrast to its antianginal effect which starts after 2-3 months of therapy.

\section{References}

Batlouni, M., Bertolami, V. \& Duprat, R. (1968) Lidoflazine na angina do peito: 1. Ensaio duplamente cego. Arquivos Brasileiros de Cardiologia, 21, 321.

BATlOUNI, M. Electrocardiografic aspects of lidoflazine treatment in patients with a,rial fibrillation. Janssen Pharmaceutica (internal report).

Benchimol, A., Lowe, H.M. \& Akre, P.R. (1965) Cardiovascular response to exercise during atrial fibrillation and after conversion to sinus rhythm. American Journal of Cardiology, 16, 31.

Bernstein, V. \& Peretz, D.I. (1972) Lidoflazine, a new drug in the treatment of angina pectoris. Current Therapeutic Research, 14, 483.

Blizzard, J.J. \& RUPP, J.J. (1960) Prolongation of the PR interval as a manifestation of thyrotoxicosis. Journal of the American Medical Association, 173, 1845.

Bock, D. \& KLEIN, E. (1972) Elektrokardiographische Befunde bei Hyperthyreosen. Zeitschrift für Allgemein Medizin/Der Landarzt, 48, 1031.

Boone, J.A. (1945) Ventricular fibrillation as a complication of hyperthyroidism. American Heart Journal, 29, 751.

Bouma, H.G.D. \& MAY, J.F. (1967) Boezemfibrilleren, sinusritme en hartminutenvolume. Nederlands Tijdschrift voor Geneeskunde, 111, 152.

Bourel, M., Gouffault, J., Lenoir, P., Guillou, M., Simon, M. \& MURIE, N. (1969) Le coeur dans l'hyperthyroidie. Semaine des Hopitaux de Paris, 45, 893.

Canary, J.J., SchaAP, M., Duffy, B.J. \& Kyle, L.H. (1957) Effects of oral and intramuscular administration of reserpine in thyrotoxicosis. New England Journal of Medicine, 257, 435 .
Carlier, J. (1973) Le traitement des complications cardiaques de l'hyperthyroidie. Revue Médicale de Liège, 28, 601 .

Carmeliet, E. \& Xhonneux, R. (1971) Influence of lidoflazine on cardiac transmembrane potentials and experimental arrhythmias. Naunyn-Schmiedebergs Archiv für experimentelle Pathologie und Pharmakologie, 268, 210.

Cookson, H. (1959) The thyroid and the heart. British Medical Journal, i, 254.

Davis, A.G. \& Smith, H.L. (1933) Complete heart block in hyperthyroidism following acute infections. American Heart Journal, 9, 81.

De Vil, Ch. \& BruYneel, K. (1974) Cardioversion and treatment of chronic atrial dysrhythmias with quinidine or lidoflazine. Comparative study. Acta cardiologica, 29, No. 5.

Digilio, V.A. (1938) Reversible bundle branch block in a case of hyperthyroidism. American Heart Journal, 15, 116.

ERnStene, A.C. (1938) Cardiovascular complications of hyperthyroidism. American Journal of the Medical Sciences, 195, 248.

FAIRHURST, B.J. \& SASH, L. (1959) Ventricular tachycardia associated with thyrotoxicosis. British Medical Journal, ii, 677.

FrIEDBERG, C.K. (1966) In: Diseases of the Heart, p. 1617. W. B. Saunders: Philadelphia.

GoldsteIN, S. \& KILliP, T. (1965) Catecholamine depletion in thyrotoxicosis. Effect of guanethidine on cardiovascular dynamics. Circulation, 31, 219.

HoffMAN, I., \& LowREY, R.D. (1960) The electrocardiogram in thyrotoxicosis. American Journal of Cardiology, 6, 893.

HowITT, G. \& Rowlands, D.J. (1966) Beta sympathetic blockade in hyperthyroidism. Lancet, i, 628.

HowitT, G. \& Rowlands, D.J. (1967) The heart in hyperthyroidism. American Heart Journal, 73, 282.

JAGENEAU, A.H.M., Schaper, W.K.A. \& VAN Gerven, W. (1969) Enhancement of coronary reactive hyperemia in unanaesthetized pigs by an adenosine-potentiator (lidoflazine). Naunyn-Schmiedebergs Archiv für experimentelle Pathologie und Pharmakologie, 265, 16.

JERVELL, A. (1952) Auricular fibrillation in thyrotoxicosis with special regard to the indication for quinidine therapy. Acta medica scandinavica, suppl. 266, 142, 585.

KeRnoff, L.M., Rossouw, J.E. \& KenNelly, B.M. (1972) Complete heart block complicating thyrotoxicosis. South African Medical Journal, 47, 513.

Keulen, U. (1973) A double-blind clinical and ECG evaluation of lidoflazine in the treatment of stabilized angina pectoris. Current Medical Research and Opinion, 1, 469.

Kulbertus, H. (1973) Etats d'hyperfonctionnement thyroïdien et troubles du rhythme cardiaque. Revue Médicale de Liège, 28, 595.

LANFRANChI, J.M. \& FAuChIER, J.P. (1973) Hyperthyroïdie et troubles de la conduction auriculo ventriculaire. Coeur et Médecine Interne, 12, 371.

LeE, W.Y., Bronsky, D. \& Waldstern, S.S. (1962). Studies of thyroid and sympathetic nervous system interrelationships. II. Effects of guanethidine on manifestations of hyperthyroidism. Journal of Clinical Endocrinology and Metabolism, 22, 879.

Levi, G.F. \& Proto, C. (1972) Combined treatment of atrial fibrillation with quinidine and $\beta$-blockers. British Heart Journal, 34, 911.

LYNGBORG, K. \& JACOBSEN, J.G. (1972) Intractable paroxysmal tachycardia in thyrotoxicosis simulating myocardial infarction. Acta medica scandinavica, 192, 427.

Miyahara, M., Limura, O., Yokoyama, M. \& Hoshikawa, K. (1969) Lidoflazine as an anti-arrhythmic drug. Tohoku Journal of Experimental Medicine, $97,95$.

MoE, G.K. (1968) A conceptual model of atrial fibrillation. Journal of Electrocardiology, 1, 145. 
Muggia, A.L., Stjernholm, M. \& Houle, T. (1970) Complete heart block with thyrotoxic myocarditis (report of a case). New England Journal of Medicine, 283, 1099.

Piessens, J., Kesteloot, H. \& De Geest, H. (1970) Lidoflazine in the treatment of chronic atrial fibrillation. Arzneimittel-Forschung, 20, 355.

Piessens, J. \& DE Geest, H. (1972) Longterm evaluation of lidoflazine in angina pectoris based on exercise tolerance. Cardiology, 57, 135.

RoHRBACH, J. (1968) Maskierte Hyperthyreosenals Ursache kardialer Störungen. Zeitschrift für die Gesamte Innere Medizin, 23, 680.

Rosenblum, R. \& Delman, A.J. (1963) First degree heart block associated with thyrotoxicosis. Archives of Internal Medicine, 112, 488.

SANDler, G. \& Wilson, G.M. (1959) The nature and prognosis of heart disease in thyrotoxicosis. Quarterly Journal of Medicine, 28, 347.

SCHLEPPER, M. \& DERRo, R. (1972) Antifibrillation effects of lidoflazine. Arzneimittel-Forschung, 22, 923.
Schrire, V. (1971) In: Clinical Cardiology, p. 596. Staples Press: London.

Silver, S., Delit, C. \& Eller, M. (1962) The treatment of thyrocardiac disease with radioactive iodine. Progress in Cardiovascular Disease, 5, 64.

Stern, M.P., Jacobs, R.L. \& Duncan, G.W. (1970) Complete heart block complicating hyperthyroidism. Journal of the American Medical Association, 212, 2117.

STEUER, L.G. (1936) Complete heart block in hyperthyroidism. American Heart Journal, 11, 623.

Symons, C., Richardson, P.J. \& Wood, J.B. (1971) Unusual presentation of thyrocardiac disease. Lancet, ii, 1163.

Ticzon, A.R. \& Whalen, R.W. (1973) Refractory supraventricular tachycardias. Circulation, 47, 642.

WAldstein, S.S., West, G.H., LeE, W.Y. \& Bronsky, D. (1964) Guanethidine in hyperthyroidism. Journal of the American Medical Association, 189, 609.

Willius, F.A., Boothiy, W.M. \& Wilson, L.B. (1923) The heart in exophthalmic goiter and adenoma with hyperthyroidism. Medical Clinics of North America, 7, 189. 